\title{
JONAS E $O$ ENALTECIMENTO DA HEURÍSTICA: A RESPONSABILIDADE FRENTE AO FUTURO AMEAÇADO
}

\author{
Jovino Pizzi \\ Universidade Federal de Pelotas
}

\begin{abstract}
Hans Jonas considers the future dimension of the human action. Maybe this projection is originated from his connection with the Judaism. He is a writer that belongs to a modern philosophy with post-metaphysics bases, in which the future notion was absent. The discussion became more important with the progress of the science. It projected a life style closer to the science possibilities than the metaphysic and onto-theologies aspects. By Jonas, the dialog between philosophy and sciences starts again the reflection about the future. The future is an aspect connected to the next generations and also related to the planet itself.
\end{abstract}

Keywords: Jonas and the Heuristic; Secular Morals; Global Ethics.

Resumo: Jonas enfoca a dimensão futura do agir humano. De certa forma, essa projeção nasce de sua vinculação com o judaísmo. $O$ autor se insere no contexto da filosofia moderna alicerçada em um pensamento pós-metafísico, em que a noção de futuro permaneceu ausente. 0 debate ganhou espaço com o avanço da ciência, que projetou um estilo de vida muito mais próximo às possibilidades da própria ciência do que em relação aos aspectos metafísicos ou ontoteológicos. Com Jonas, o diálogo da filosofia com as ciências retoma a reflexão acerca do futuro, aspecto ligado ao devir das próximas gerações e também em relação ao próprio planeta.

Palavras-Chave: Jonas e Heurística; Moral Secular; Ética Global.

\section{Introdução}

Para Jonas, as gerações atuais têm o compromisso de tornar possível a continuidade da vida e a sobrevivência das gerações futuras. Para tanto, é necessário rever o poder da ciência. Ele se propõe a compreender a estrutura 
do pensamento moderno e oferecer uma alternativa ao modelo cientificista. Além do diálogo com a ciência, tais questões exigem ainda uma auto-reflexão sobre a razão secularizada. A proliferação de teorias científicas é uma das características fundamentais da ciência atual. Nesse horizonte, Kuhn, Feyerabend, Popper, Lakatos e outros pretendem estabelecer um programa de pesquisa científico, estimulando mudanças metodológicas no sentido de compreender a estrutura conceitual das teorias científicas.

A filosofia não pode isolar-se e rechaçar o diálogo com pensadores voltados às problemáticas do tempo presente (e futuro). No entanto, as transformações salientam a capacidade de a filosofia justificar a fundamentação racional, sem utilizar, para tanto, fundamentos externos a ela. Nesse caso, a fundamentação do âmbito moral encontra, na razão secularizada, os argumentos para justificar o ponto de vista moral e, ao mesmo tempo, os caminhos para dialogar com a ciência.

O desenvolvimento do assunto inicia associando o imperativo da responsabilidade moral à auto-compreensão de uma racionalidade laica para, em seguida, destacar os riscos que Colborn, Dumanoski e Myers identificam frente ao atual uso indiscriminado de agentes químicos sintéticos. A continuação retoma o programa da heurística, salientado aspectos louváveis dessa idéia para, então, finalizar com o tema de uma ética secular para a responsabilidade solidaria global.

\section{A responsabilidade fundamentada na moral secularizada}

O imperativo da responsabilidade moral se vincula a auto-compreensão da razão pós-metafísica, resultado do desencantamento das imagens religiosometafísicas do mundo e o nascimento das estruturas de consciência modernas (HABERMAS, 1988, p. 249). Ao deixar de lado tais imagens, a filosofia já não arroga mais "fundamentos ontoteológicos ou cosmológicos para modelos universalmente vinculantes” (Idem, 2006, p. 276). Daí, o moral point of view ligado aos interesses de todos, renunciando, portanto, toda perspectiva substancial de uma forma de vida particular, às vezes, externa e alheia ao sujeito. Além do âmbito moral, aspectos como a educação e a política foram sendo, aos poucos, assumidas pelo Estado secular. Porém, "antigamente a Igreja, por exemplo, ela própria como uma instituição pública, se encarregava" dessas tarefas (JONAS, 2006, p. 181, nota ao pé da página). Por isso, a destrancendentalização e a linguisticização da filosofia fomentaram uma "moral laica secularizada", de 
forma que a "consciência moral civil" ganhou autonomia frente às perspectivas cosmológicas e religiosas, possibilitando uma "ética regida por princípios" (HABERMAS, 1988, p. 301).

Além disso, há outro aspecto significativo. Para Habermas, "o vigor afirmativo das éticas clássicas já se esvaeceu faz um bom tempo” (Idem, 2009, p. 217). Por isso, não se justifica apenas uma genealogia da tradição moral ocidental e de seus aspectos semânticos e simbólicos, mas em estudar e debater as características da "razão prática emancipada" (Idem, 1988, p. 302). O potencial da moral laica e de sua peculiar influência na vida das pessoas concedeu aos sujeitos uma autonomia frente às tradições mítico-religiosas. $\mathrm{Na}$ verdade, ela própria se emancipou de qualquer dependência alheia e externa. Em razão disso, os sujeitos devem arcar com a responsabilidade na busca dos fundamentos da moral, cobrando-lhes não apenas a imputabilidade pelas ações no presente, mas também nas prerrogativas de sua conduta frente a um possível futuro sustentado e saudável.

O debate em torno à secularização sofreu modificações no decorrer dos anos 80 e 90 do século passado. Todavia, foi neste século que ele ganhou contornos ainda mais precisos. Atualmente, o imperativo da responsabilidade permeia o núcleo moral dos diferentes discursos públicos e processos políticos. Essa convergência tem por base uma moral secular que, embora sofra constantes ataques, reclama um programa filosófico capaz de garantir a autonomia do sujeito frente às questões substancialistas. $\mathrm{Na}$ verdade, não há como fugir da discussão a respeito da "forma como as cosmovisões, sejam metafísicas ou religiosas, são traduzidas simbolicamente por meio da abertura ao tratamento discursivo ou lingüístico" (MENDIETA, 2001, p. 42). Nesse debate, não se deve confundir a linguagem religiosa com a peculiaridade da compreensão filosófica. A tradição religiosa visa descortinar os "vestígios que apontam para algo inacessível de modo direto” (RABUSKE, 1987, p. 123). Nela, a tarefa da razão se reduz à tentativa de captar o sentido daquilo que está "escondido", isto é, o misterioso e, portanto, externo ao mundo intrinsecamente vivencial dos sujeitos comunicativos.

O abandono da fundamentação ontoteológica ou cosmológica modificou os cânones da ética. As éticas tradicionais procuravam determinar com clareza e sem dificuldades o bem humano, pois o agir e, em decorrência, a responsabilidade humana estava delineada por pressupostos aceitos sem nenhuma crítica. Além disso, essa mudança ética indica, segundo Bonilla, o abandono de "seus objetos característicos de modo tal que pouco incidiram 
nos assuntos práticos que foram aparecendo como consequência do desenvolvimento das ciências e da tecnologia ou da dinâmica específica da vida social” (BONILLA, 2006, p. 78).

As mudanças são profundas e, por isso, a era da ciência significou uma nova configuração ou, então, um novo desenho para a ética, rompendo com o antropocentrismo (JONAS, 1997, p. 35). Ela não se limita à fundamentação de normas e princípios, pois se preocupava com os diferentes âmbitos da vida prática: meio ambiente, economia, empresas, a genética e a manipulação humana e outros aspectos mais (PIZZI, 2010). Essa inquietação não é apenas tema para a filosofia; é objeto de investigação para cientistas, economistas, administradores de empresas, ambientalistas, etc., pois envolve tanto o presente do planeta como também as gerações futuras.

O giro aplicado da filosofia tenta superar os déficits de uma ética antropocentrada, preocupada em garantir a essência humana diante dos demais seres e da natureza. Ela se militava à promoção do bem humano (JONAS, 1997, p. 35). No caso, as anomalias ou as irregularidades eram provenientes do desconhecido (deuses, caos, destino, essência, etc). A mudança envolve também as demais ciências, pois tal perspectiva ética é incapaz de assimilar as relações com os seres não-humanos.

O imperativo da responsabilidade moral foi, sem dúvida, uma decorrência desse giro aplicado da filosofia, com características seculares. Essa preocupação prática remete ao aspecto problemático e nebuloso da responsabilidade, pois muitas pessoas são "cobaias" inconscientes, isto é, não entendem os efeitos provocados por agentes químicos sintéticos. Atualmente, a economia e o desenvolvimento estão embasados sobre "um alicerce de combustíveis fósseis e químicos sintéticos (COLBORN e outros, 2002, p. 275). Esses agentes são decisivos para as gerações futuras. $\mathrm{Na}$ verdade, para muitos, o futuro simplesmente foi subtraído; para outros, ele é negro, ou seja, uma possível conseqüência dramática, pois ultrapassa as medidas ou o grau habitual dos dados de forma que inexiste informação a respeito, mas que ninguém pode fugir. Utilizando outra analogia, o futuro seria um tipo de caixa preta cujas informações são, na prática, enigmáticas ou, então, que persistem sem explicação.

\section{O futuro: negropara uns, ameaçado para outros}

Como foi salientado, a responsabilidade moral se vincula a uma autocompreensão racional ligada ao âmbito secular. Essa conotação está 
submetida à dinâmica do progresso orientado ao domínio humano sobre a natureza. Para Jonas, "o reino dos homens é o de uma natureza por ele dominada” (JONAS, 2005, p. 339). De certa forma, a ética antropocentrada resume a responsabilidade a uma opção particular frente aos padecimentos dos sofredores, de forma que o bom ou o mal estão delineados previamente. Assim, a responsabilidade com o bem comum era, por natureza, artificial e antinatural (Idem, p. 350).

Os impactos de qualquer ação têm repercussões futuras. As consequências dos diferentes desastres provocados pela ação humana e a contaminação do meio ambiente - British Petroleum, Chernobyl, Prestige e inúmeros outros casos - ressoam na opinião pública. A própria rotulagem dos Organismos Geneticamente Modificados é um dilema (PIZZI, 2006, p. 43). Atualmente, é sensível a preocupação em torno aos agentes químicos sintéticos e às modificações que eles provocam nos seres vivos e na natureza, alterando a estrutura e a personalidade não só de humanos, mas também de não-humanos, interferindo, até mesmo, no equilíbrio da própria natureza.

Diante disso, a filosofia não deve isolar-se e rechaçar o diálogo com a ciência, nem com os cientistas. Nesse diálogo, é esclarecedor o livro Our Stolen Future (1996) de Colborn, Dumanoski e Myers ( $O$ futuro roubado, 2005). A obra descreve a maneira como os agentes químicos sintéticos alteram os vulneráveis sistemas hormonais dos seres humanos e nãohumanos, gerando distúrbios funcionais e metabólicos, incidindo até mesmo na fertilidade e na inteligência das pessoas. De certa forma, o livro parece dar continuidade à preocupação de Jonas, revelando dados até então desconhecidos. $\mathrm{O}$ estudo relaciona os problemas oriundos do uso indiscriminado de agentes químicos. Os autores salientam a infertilidade (ou diminuição de espermatozóides) e deformações genitais, cânceres (de mama e próstata), desordens neurológicas em crianças (como hiperatividade e déficit de atenção) e questões ligadas ao desenvolvimento e à reprodução (principalmente em animais silvestres), entre outros.

Para compreender a amplitude da questão, o livro destaca uma série de exemplos. Um deles diz respeito a uma mulher (Andréa), cuja mãe utilizou, durante a gravidez, o DES (dietilestilbestrol), um medicamento estrogênio empregado, entre outras aplicações, no tratamento da insuficiência ovárica. Depois de muitos exames, os médicos descobriram que Andrea "era uma das filhas do DES” e apresentava um útero anômalo, isto é, “severamente deformado" (COLBORN e outros, 2005, p. 75). 
Em relação aos humanos, há outro exemplo relacionado às conseqüências desses agentes químicos. Sem uma comprovação mais ampla, pesquisadores contataram efeitos também sobre o rendimento escolar, uma vez que os contaminantes comprometem "o desenvolvimento mental a ponto de causar uma perda de cinco pontos no QI mensurável” (Idem, 2005, p. 74). Vejamos isso mais detalhadamente:

Atualmente, o QI médio é de 100 pontos. Uma população de 100 milhões de pessoas tem 2,3 milhões intelectualmente privilegiadas, cujo QI está acima de 130. Embora não pareça muito, se o QI médio caísse apenas cinco pontos, para 95, as implicações seriam vertiginosas [...]. Ao invés de 2,3 milhões, apenas 990 mil pessoas teriam um QI acima de 130, de forma que a sociedade perderia mais da metade de suas mentes privilegiadas, com capacidade para se tornarem os melhores médicos, cientistas, professores universitários, inventores ou escritores (Idem, 2005, p. 265).

Mesmo que isso pareça uma simples fantasia, a questão redefine os denominados problemas sociais e as temáticas educacionais, pois se os agentes químicos sintéticos podem alterar os hormônios da tireóide (vitais para o desenvolvimento do cérebro), não há como negar que determinadas mudanças comportamentais têm relação com esses agentes químicos. Vale dizer, a contaminação química é um "fator que contribui para aumentar os casos de comportamento não-funcional também na sociedade humana” (Idem, 2005, p. 268).

A responsabilidade frente ao futuro apresenta, portanto, um dilema. A comparação feita pelos autores do livro foi retratada da seguinte forma:

(...) é como o de um avião no meio da neblina, sem mapas ou instrumentos. Em vez de serem capazes de gerar um sistema confiável de radar, nossos cientistas estão espiando pela janela da cabine tentando nos avisar sobre os obstáculos que temos à frente. E, normalmente, o melhor que eles estão podendo fazer é informar que a massa escura que está entrando no nosso campo de visão pode ser uma barreira de nuvens. Ou, quem sabe, uma montanha (Idem, p. 276). 
De fato, há uma espécie de buraco negro a respeito das possíveis conseqüências do avanço científico. Por isso, os impactos desse "poder formidável e sem precedentes da ciência e da tecnologia” se defrontam com as exigências normativas de uma vida saudável, tanto para humanos como para não-humanos e do próprio planeta. Nesse dilema, "todos somos cobaias", pois os "químicos sintéticos se espalharam tanto pelo ambiente como invadiram nossos corpos, a tal ponto que não é mais possível definir qualquer fisiologia humana como normal ou inalterada" (COLBORN e outros, 2005, p. 270). De acordo com esses estudiosos, todos nós já adquirimos uma "carga considerável de agentes químicos persistentes." $\mathrm{E}$ mais: "nenhuma criança nasce hoje livre destes químicos" (Idem, p. 270).

Será que devemos assumir a responsabilidade diante dos riscos desses agentes? Por que a filosofia deve preocupar-se com isso? Será apenas uma questão momentânea? Como tratar dessas questões? Como transformar essa preocupação em tema para a filosofia? A filosofia deve contribuir nesse debate? De que forma?

Para Habermas, a modernidade produziu uma perspectiva filosófica que se reabastece em suas próprias fontes, mas apresenta, todavia, "debilidades motivacionais de uma moral racional" que apenas podem ser asseguradas nos "limites do Estado constitucional democrático através do direito positivo" (HABERMAS, 2009, p. 221). O problema está na progressiva perda da sensibilidade, ou seja, as percepções de um compromisso moral não impedem em nada o encantamento diante do progresso da ciência. Além do mais, há um receio em trazer para o debate filosófico a própria idéia de futuro. Nesse sentido, me pergunto se o simples ato de sentarmos à mesa e nos alimentar se resume ao fato de matar a fome ou de provar os sabores dos alimentos. Ou, então, se o ato de dormir representa tão e somente uma oportunidade para sonhar. E mais: fazer higiene é simplesmente uma questão estética.

Então, se, por um lado, estamos submetidos a um determinismo causal em relação às leis da natureza, é evidente que, por outro, não há porque condicionar a vida presente e futura aos caprichos da ciência ou às fantasias de um bem-estar circunstancial. Por isso, não devemos decidir o que as gerações futuras querem ser e como desejariam viver; simplesmente, não há como negarlhes a possibilidade de que elas possam existir; nada mais que isso. Como é possível perceber, há seres vivos despojados da possibilidade de viver, enquanto muitos outros estão ameaçados da condição propícia para persistirem. 
Em parte, o foco eminentemente presencial das pretensões é uma herança da era tecnológica. A inquietação com "o que há de vir” continuou ligado às tradições religiosas. A filosofia atual assumiu o ideal de vida considerando apenas o presente. Essa limitação ao bem-estar progride de modo proporcional ao crescimento dos "imperativos do mercado na forma de custos-benefício-cálculos ou da competência de serviços em âmbitos da vida cada vez mais variados, os quais obrigam aos indivíduos, na sua relação com os demais, a uma atitude objetivista” (HABERMAS, 2009, p. 218). Como crítico, Habermas faz menção a um processo de cientificização das sociedades modernas e das relações humanas, priorizando a instrumentalização das relações sociais, mesmo que as pessoas, no fundo, conservem a consciência moral e acreditem em uma justiça social e na solidariedade.

Por isso, a racionalidade comunicativa, além de garantir vínculos relevantes entre os sujeitos, está em supor a solidariedade, os compromissos de justiça e, inclusive, a responsabilidade frente ao futuro. Este é, sem dúvidas, o desafio de uma perspectiva universalista disposta a não perder de vista o bom e o justificável de cada tradição.

Nesse sentido, a justiça para com os outros e com um possível futuro não se reduz à benevolência, empatia, intuição ou ao cuidado, mas à responsabilidade. No fundo, justiça e solidariedade não são "princípios morais diferentes, mas dois aspectos de um mesmo princípio" (COHEN e ARATO, 2000, p. 425). Dessa forma, a justiça ultrapassa os limites semânticos para ganhar o espaço de uma pragmática-fenomenológica, isto é, capaz de ressaltar descritivamente a experiência vivida pelos diferentes interlocutores, sem, por isso, rechaçar princípios, normas e regras de caráter universal. O sentido da justiça não separa, portanto, razão (Vernuft) de entendimento (Verstand), nem desvincula a fundamentação da sua realização prática.

\section{A heurística e 0 afiançamento do futuro}

Bem sabemos que determinadas tradições religiosas insistem na escatologia, em que o medo assume proporções significativas: medo do inferno e, por isso, "não cair em tentação" é o slogan propalado, assim como fazer sacrifício para expiar os pecados é a insígnia para a proposta adequada. A idéia de condenação é per se assustadora e causadora de fobias paralisantes. Evidentemente, o fenômeno religioso tem um viés mais otimista, o da 
redenção. No entanto, a morte ou a "transfiguração" da religião, como diz Vattimo, sofre de um "mal estar" interno, pois determinadas atitudes vão debilitando sensivelmente os próprios argumentos religiosos. Nesse sentido, há diferenças profundas entre a relação fé e ciência no diálogo entre filosofia e ciência, uma vez que as religiões tendem a delimitar a conduta a partir dos dogmas, que são, em tese, inquestionáveis.

O tema das religiões indica "um programa antigo" na tradição ocidental. Não estaria Jonas imerso nesse sentimento? Em parte sim, pois se situa no contexto de uma moral pós-metafísica, ou seja, no horizonte de um mundo secular. Por um lado, isso significa o rechaço de qualquer pretensão substancialista, mas, por outro, esse contexto filosófico procura também assegurar um lugar às pretensões mítico-religiosas. Jonas se alimenta da tradição judaico-talmúdica, perspectiva que permeia seu pensamento e, no caso, contamina seu processo de fundamentação filosófica. Esse também é o problema de Levinas, apenas para lembrar outro filósofo dessa tradição. Jonas parece tomar algumas precauções em torno a isso, enquanto Levinas assume abertamente esse viés. Embora a crítica a Kant possa aparentar certa plausibilidade, Hans Jonas se insere em uma linha de reflexão que insiste na necessidade de um "retorno do interesse por instituições básicas (como a família e a comunidade) e a busca de raízes históricas”, o que representa um indício de sua procura por condutas mais seguras e valores mais duradouros em um mundo cambiante (HARLEY, 1994, p. 263).

A tese de Jonas advém da inquietação com o futuro e os "efeitos de longo prazo", ou seja, das "projeções futuras", como ele mesmo salienta (JONAS, 2006, p. 72 ss). Então, se as religiões supõem uma perspectiva escatológica, a ética também deve, de acordo com Jonas, asseverar um âmbito com o caráter prospectivo. Todavia, como tornar visíveis os aspectos conjecturais? Como transformar as projeções de futuro em algo palpável? As probabilidades da science fiction podem até ser mensuráveis, mas de que modo investigar e descobrir princípios ainda desconhecidos?

Para responder essas indagações, Jonas evoca a "casuística heurística" como faculdade capaz de projetar os efeitos prováveis do conhecimento científico. Para ele, essas tarefas "só se viabilizam por meio da ciência, da mesma forma essa extrapolação requer, no mínimo, o mesmo grau de ciência utilizado nos próprios empreendimentos" (JONAS, 2006, p. 73). Tal metodologia, embora consiga realizar "prognósticos de curto prazo", é incapaz de produzir prognósticos de longo prazo. Daí, então, o papel da ética como 
"extrapolandum tecnológico", ou seja, um saber pertencente "à esfera ideal” não limitado à "certeza das projeções científicas” (JONAS, 2006, p. 74). Cabe, pois, à ética orientar as decisões "sobre o que fazer agora e ao que renunciar, exigindo-se assim uma considerável certeza da previsão, que justifique a renúncia a um desejável efeito próximo em favor de um efeito distante" (JONAS, 2006, p. 74). Embora tal efeito remoto não afete as gerações atuais, não cabe à ciência, mas à filosofia (vale dizer, à ética) a orientação normativa do agir. Essa projeção obedece a um procedimento metodológico, de modo que o conhecimento do possível seja heuristicamente suficiente. No caso, cabe à ética a diferenciação do mau prognóstico sobre o bom.

Ao bem da verdade, Lakatos (1922-1974), com a obra Metodologia dos programas de investigação científica (1970), redimensionou a epistemologia, transformando-a em "metodologia dos programas de pesquisa científica." Estreitamente ligado à "explicação lógica para o fazer científico", o autor repensou a filosofia de Popper (GARCÍA-BARRÓN, 1998, p. 1380). Para Lakatos, a expressão "programas de pesquisa" é mais apropriada do que a de paradigma, porque a disputa pode ocorrer dentro do mesmo paradigma, e não apenas entre paradigmas distintos (D’AGOSTINI, 2002, p. 614). Afastando-se de Kuhn, Lakatos afirma que a história da ciência não é a história de teorias sucessivas, mas "de teorias concorrentes" (BORGES NETO, 2010, p. 1).

Em razão disso, Lakatos redesenha a projeção dos efeitos do conhecimento científico através de um núcleo sólido e de uma heurística. $\mathrm{O}$ primeiro aspecto refere-se ao

conjunto de proposições metafísicas, isto é, proposições que
por decisão metodológica são dadas como não testáveis. A
heurística é um conjunto de regras metodológicas e pode ser
vista como a conjunção de uma heurística negativa, que
consiste em regras que nos dizem que direções de pesquisa
devem ser evitadas, e uma heurística positiva, que são regras
que indicam as direções a serem seguidas (BORGES NETO,
2010, p. 2).

De outra forma, a heurística se retroalimenta através de dois âmbitos. $\mathrm{Na}$ interpretação de A. Berten, a heurística negativa representa um 
conjunto de hipóteses teóricas muito genéricas que estão imunizadas contra toda tentativa de refutação. Isso não significa que elas sejam falsificáveis, mas que existe uma decisão tácita de não colocá-las em questão. Trata-se de um "núcleo sólido" a partir do qual todas as pesquisas adquirem sentido (por exemplo, a existência do inconsciente na psicanálise, ou a determinação em última instância da economia no marxismo). Este "núcleo sólido" é prolongado por um "cinto protetor": um conjunto de hipóteses auxiliares, eventualmente modificáveis, permitindo imunizar o núcleo teórico (por exemplo, pode-se discutir se o dualismo fundamental está entre pulso sexual/pulsão do eu, ou ainda, entre pulsão de vida/pulsão de morte) (2004, p. 32-33).

Como é possível perceber, as proposições do núcleo duro são protegidas das refutações e, ainda, impedem "tentativas de explicações de tipo radicalmente diferentes das explicações aconselhadas pela heurística positiva" (BORGES NETO, 2010, p. 2). O núcleo sólido permite desenvolver interpretações esclarecedoras desde um conjunto de condições iniciais, que, apesar de genéricas, garante justificativas razoáveis às hipóteses decorrentes da proposição inicial. Os programas de pesquisa são complexos, por serem realidades "formadas por um núcleo de assuntos fundamentais, o qual é, por sua vez, circundado por uma cintura protetora de hipóteses auxiliares" (D’AGOSTINI, 2002, p. 614). As condições iniciais formam o núcleo sólido mais consistente e, por isso, permanece intacto por mais tempo, ao passo que as hipóteses auxiliares são mais débeis e refutáveis; portanto, falsificáveis sem grandes dificuldades.

Por sua vez, a heurística positiva, segundo Berten, preocupa-se com as

indicações e orientações sobre os programas de pesquisa a serem desenvolvidos. Trata-se de hipóteses secundárias visando dar conta dos fenômenos já conhecidos e prever novos; trata-se ainda de melhorar os instrumentos técnicos, de elucidar questões que permanecem pendentes etc. A heurística positiva é uma espécie de agenda, indicando quais são os problemas essenciais, estabelecendo uma forma de hierarquia entre as pesquisas desenvolvidas (2004, p. 33). 
Mesmo débeis e facilmente falsificáveis, esses programas de pesquisa não podem ser descartados, e sim protegidos; pois é necessário salientar suas potencialidades. Por isso, deve-se explorar todas elas para ver até que ponto as hipóteses secundárias progridem ou regridem. Na verdade, trata-se de uma "política de desenvolvimento" dos programas de pesquisa através da "seleção e ordenamento de problemas" (BORGES NETO, 2010, p. 2). No início, ninguém se preocupa em falsear ou confirmar as hipóteses, pois à medida que um programa vai avançando, passa a ganhar preferência; quando seu caráter não progride, perde plausibilidade. A tese da "não-implausibilidade de uma teoria falsificada ou falsificável” está vinculada aos programas de pesquisa. As teorias são "compostas de um núcleo interno e de hipóteses de sustentação: o núcleo pode ser frágil, mas somente porque as hipóteses auxiliares ainda não estão bem estruturadas” (D’AGOSTINI, 2002, p. 614).

Para D’Agostini, "o resultado é a reabilitação da razão, realizada no próprio terreno (que a outros parecia desagregador) da história da ciência” (Idem, 2002, p. 615). Em outras palavras, Lakatos é racionalista, não só em relação ao progresso científico, pois ele procura elaborar "as condições universais" de cientificidade de uma teoria (BERTEN, 2002, p. 34). Sua proposta reflete uma metodologia capaz de conduzir à reconstrução racional e factual do procedimento científico, definindo as bases de uma heurística, isto é, "um método que permite orientar a pesquisa" (BERTEN, 2002, p. 32).

Jonas pretende ampliar o programa da pesquisa científica e aplicá-lo ao contexto de uma sociedade tecnológica. Ele não se limita à compreensão da ciência, pois vincula à sua concepção filosófica uma estrutura conceitual ligada à heurística (heruristic of fear). A suposição ou a espécie de adivinhação a respeito do futuro gera incertezas. Por isso, a tentativa de previsão (2006, p. 193) ou predição (p. 194) “do que virá” necessita de uma idéia antecipada de suas possíveis conseqüências. A "capacidade de previsão" significa que o sujeito deve ter o controle dos fatos. As previsões, segundo Jonas, exigem que uma teoria não seja enganosa quanto aos seus resultados, principalmente a longo prazo. Nesse sentido, ele menciona o exemplo de Lenin, que "não se enganou quanto ao fato de que sua ação provocaria uma reviravolta mundial que imprimiria nova direção ao curso das coisas durante muitas gerações, ou talvez para sempre” (JONAS, 2006, p. 194).

Para ser fiel à verdade, a heurística reverencia um apelo prudencial, ou seja, o delineamento das teorias científicas no sentido de estudar e examinar também os efeitos futuros de suas proposições. A heruristic of fear tenderia a 
desacomodar diante do aparente sonho maravilhoso da tecnologia. No idioma espanhol, a tradução da palavra encomiable refere-se a algo louvável, encarecido e elogiável. O temor exige uma abertura a ele e, então, perceber os riscos da devastação. Diante da dúvida, o aspecto prudencial recomenda dar atenção ao pior prognóstico e não ao melhor: in dúbio pro malo (JONAS, 1997, p. 48). O fato de acentuar a moral laica denuncia que a ciência e a técnica assumem, às vezes, as figuras de deusas salvadoras e redentoras de qualquer vulnerabilidade, inclusive da morte. Atualmente, o agir humano encontra-se, por assim dizer, coagido pelo sentimento de responsabilidade frente ao futuro. No fundo, os prognósticos representam um alerta diante dos perigos e dos riscos que a vida como tal se defronta.

Tendo em vista o delineamento de Lakatos, pode-se inferir que o programa de Jonas conserva a estrutura da heurística em duas direções. Por um lado, o núcleo duro, isto é, "a permanência imprescindível de um dever" e, por outro, projeções que "podem ser corrigidas a qualquer momento, sem prejuízo do método como um todo” (2006, p. 196). A justeza incondicional do método heurístico depende, portanto, da sintonia entre a heurística negativa e a positiva. Por um lado, o núcleo sustentador se apresenta como condição imprescindível para qualquer teoria e, por outro, uma diversidade de hipóteses auxiliares (ou secundárias) relacionadas aos problemas essenciais dos programas de pesquisa.

Jonas entende que o aspecto fundamental não se relaciona ao âmbito factual do desenvolvimento da ciência em si, mas na direção e das possíveis conseqüências desse progresso. Por isso, ele propõe a substituição do modelo cartesiano/baconiado por um novo, não intervencionista. A relação com a natureza não é linear, contínua e/ou ilimitada (JONAS, 1997, p. 18 e 21). Além da imputabilidade da responsabilidade pelos atos, é preciso limitar os poderes do progresso técnico, ou seja, poder "corrigir seus próprios efeitos" (idem, 1997, p. 51). Trata-se, pois, de elaborar uma nova filosofia da natureza, uma reconstrução biotecnológica para os seres vivos. Sem a heurística, "não saberíamos agir de maneira responsável se não fôssemos capazes de estremecer diante de algumas possibilidades” (GOFFI, 2003, I, p. 861). No fundo, os dados evidenciam uma projeção não muito clara em relação ao modelo de desenvolvimento e a forma como a tecnologia vem sendo utilizada. Por isso, a responsabilidade não é uma atitude individual, um sentimento de compaixão ou de piedade, pois requer uma responsabilidade global. 


\section{A ética secular em vistas à responsabilidade global}

A dissolução das justificativas mítico-narrativas incide determinantemente sobre a ética atual. Em uma conotação cotidiana, pode-se afirmar que "nós fazemos ética", pois ela não depende mais de fundamentos ontoteológicos ou cosmológicos. Com a des-teologização e a destranscendentalização, a ética consegue fundamentar racionalmente princípios e normas. Apenas a racionalidade pós-metafísica, ou seja, a racionalidade éticocomunicativa promove um programa de investigação heuristicamente plausível. Neste caso, o "fazer ética" desde um ponto de vista intersubjetivo requer a busca de "pretensões de validez suscetíveis a crítica (HABERMAS, 1988, p. 107). Por isso. as pretensões de validez refutam o essencialismo éticoantropológico, refém de um salvacionismo ingênuo (DALBOSCO, 2008, p. 46-47). O fio condutor obedece a ética laica, um procedimento racional inerente ao horizonte do mundo da vida. As normas que orientam o agir são fruto desse processo comunicativo intersubjetivo entre sujeitos-participantes tendo como base a validez dos atos de fala. Os sujeitos procuram entender-se racionalmente sobre pretensões de validade normativas. E somente podem ter validade as normas aceitas por todos os participantes em um discurso prático.

Nessa perspectiva, a razão secular consegue apropriar-se, através dos recursos do pensamento pós-metafísico, dos conteúdos semânticos das tradições, superando, dessa forma, as pretensões mítico-religiosas. Essa racionalidade enfrenta, todavia, restrições de diferentes setores, principalmente dos que se apóiam em tradições conservadoras e, de certa maneira, de teses que se alimentam de perspectivas anacrônicas. Nesse caso, a volta a um passado pré-moderno seria a única alternativa plausível para indicar soluções aos problemas atuais. Essas prerrogativas são filosoficamente irrelevantes. Embora sofra de um déficit de motivação, a racionalidade laica é uma condição imprescindível para enfrentar os problemas presentes e futuros de uma sociedade pluri-, multi- e intercultural - ou, se desejarmos, podemos utilizar outras denominações como sociedade complexa, de risco, em transformação, etc.

Esse é o aspecto chave do programa filosófico enaltecedor da heurística como sendo um caminho para a responsabilidade, seja ela política, parental, educacional ou moral. Os fundamentos secularizados da moral 
asseveram os princípios normativos e a responsabilidade do Estado atual. No seu modo procedimental, essa prerrogativa assegura vínculos entre os sujeitos que acreditam na justiça social, nos laços de solidariedade e na responsabilidade em relação a um futuro possível em um horizonte de vida terrenal. Apesar das "debilidades motivacionais" para metas coletivas, essa razão secular tem sido eficiente em relação à "observância individual dos deveres”. Essa constatação indica o longo caminho pela frente, no sentido de estabelecer ações "moralmente instruídas" tanto em relação ao tempo presente quanto as perspectiva de longo prazo.

De qualquer maneira, a razão pós-metafísica se fundamenta em princípios irrenunciáveis. Seus déficits manifestam, todavia, uma preocupação frente às projeções de longo prazo. Não raras vezes, a ciência assume o protagonismo e oferece as bases teóricas para as decisões. Em grande medida, essa deficiência afeta não apenas as pessoas como tal, mas faz parte também do jogo político, no sentido de manter o status quo de uma sociedade estruturalmente organizada, instrumentalizando não apenas a relação entre os sujeitos, mas colocando também em risco a idéia de uma sociedade global e multicultural. Até mesmo os "governos influentes - que sempre são os atores políticos mais importantes deste cenário - prosseguem, sem titubear, seus jogos de poder social-darwinistas" (HABERMAS, 2009, p. 219). Em outras palavras, para Habermas, "não falta apenas vontade política para desejar instituições e processos de ordem mundial reformada, mas inclusive a perspectiva de uma política interna global satisfatória" (Idem, 2009, p. 219).

Macpherson afirma que o modelo de Rawls "satisfaz os critérios para uma teoria da justiça econômica, enquanto realmente propõe submeter os acordos distributivos a um princípio ético" (1991, p. 26). Para este autor, o problema é a forma competitiva do modelo liberal, isto é, "uma economia totalmente dominada pelo mercado no qual a reação negativa dos empresários ao incremento dos impostos faz com que diminua a produtividade global (MACPHERSON, 1991, p. 26). O mercado acaba dominando as relações, fazendo com que as exigências normativas percam sua força, de modo que a ética não pode fazer valer seus princípios.

Em relação a isso, há uma questão primordial. Para K. O. Apel, a pergunta é: em que consiste a função racional de fundamentação ligada a uma ética filosófica da responsabilidade? (2007, p. 61). 
Essa indagação suscita observações interessantes, para não dizer primordiais:

1. Em primeiro lugar, a pergunta de Apel remete a outra questão: como a ética laica pode ser transformada em uma proposta de fundamentação em vistas ao futuro? Essa é uma das indagações que o estudo de Jonas suscita, ainda mais quando se fala de secularização e na sua influência sobre as questões que ultrapassam o horizonte do antropologicamente tradicional. A racionalidade ético-comunicativa insiste na legitimação de um Estado democrático de direito neutro, isto é, capaz de promover a integração social a partir de suas próprias bases ou fundamentos. E, além disso, garantir a responsabilidade sobre a possibilidade de as gerações futuras existirem, pois uma ética voltada ao futuro indica uma "extensão temporal da responsabilidade", bem como uma "ampliação do objeto" e uma "preocupação profunda" diante das possibilidades utópicas de um sentido do agir e da responsabilidade que ainda precisa ser determinado (JONAS, 2006, p. 56).

2. O segundo aspecto diz respeito aos próprios pressupostos fundamentais dessa racionalidade. A auto-compreensão des-teologizada e destranscendentalizada garante sua neutralidade diante dos ideais de bem. Como, então, delinear os contornos de uma razão laica e neutra diante dos conteúdos semânticos que a realidade cotidiana apresenta? Como delinear a responsabilidade de modo que ela consiga motivar os sujeitos a agirem em vistas ao presente e, ao temo tempo, assumindo um compromisso em relação ao futuro?

Os programas de pesquisa filosóficos presumem, segundo Jonas, uma metodologia que não se limita ao diagnóstico do presente. Além do mais, o autor se preocupa com o "poder" da responsabilidade e "por suas conseqüências" (2006, p. 165). Não se trata, pois, de "projeções científicas”, mas do caráter normativo tanto em relação ao "efeito próximo" como "em favor de um efeito distante” (JONAS, 2006, p. 74). Nesse processo, o tema permanece aberto entre um presente dividido entre as promessas da ciência e as dúvidas que sobre ela recaem, um futuro que já foi roubado de alguns e um devenir incerto.

3. Em terceiro lugar, a moral secular, embora pareça demonstrar certa incapacidade prática para sustentar metas coletivas, o desafio está em criar mecanismos de modo que "a defesa cooperativa frente a perigos coletivos" 
ganhe a mesma importância "que a observância individual dos deveres morais" (HABERMAS, 2009, p. 223). Esse apelo "contra os perigos do tempo e contra a própria ação dos homens não é um fim utópico, mas tampouco se trata de um fim tão humilde” (JONAS, 2006, p. 353).

Nesse sentido, acredito que a grande preocupação está em saber "como devemos viver com a natureza ou como a natureza pode subsistir ao nosso lado” (JONAS, 2005, p. 360). Eu penso que a este respeito temos muito mais incertezas do que garantias. Deste modo, somos "condenados" a viver um presente diante de um futuro mais que duvidoso. 


\section{Referências Bibliográficas:}

APEL, K.-O. La globalización y una ética de la responsabilidad. Reflexiones filosóficas acerca de la globalización. Buenos Aires: Prometeo Libros, 2007.

BONILLA, A. "¿Quién es el Sujeto de la Bioética? Reflexiones sobre la vulnerabilidad”. In: LOSOVIZ, A. I.; VIDAL, D. A. \& BONILLA, A. Bioética y Salud Mental. Intersecciones y dilemas. Buenos Aires: Akadia, 2006.

BORGES NETO, J. "Imre Lakatos e a Metodologia dos Programas de Investigação Científica”.

www.diaadiaeducacao.pr.gov.br/.../lakatos_metod_prog_invest_cientif.pdf, acessado em 24 de julho de 2010.

COLBORN, T.; DUMANOSKI, D.; MYERS, J. P. O futuro roubado. Porto Alegre: L\&PM, 2002.

CORTINA, A. Alianza y contrato. Política, ética y religión. Madrid: Trotta, 2001.

D’AGOSTINI, F. Analíticos e continentais. São Leopoldo: Editora Unisinos, 2002.

DALBOSCO, C. A. "Filosofia e formação docente". In: KUIAVA, E. A. e Outros. Filosofia, formação docente e cidadania. Ijuí: Editora Unijuí, 2008.

GOFFI, J. Y. “Jonas, Hans, 1903-1993”. In: CANTO-SPERBER, M. Dicionário de ética e filosofía moral. São Leopoldo: Editora Unisinos, 2003, V. 1.

GARCÍA-BARRÓN, J. C. Historia de la filosofia. III. Siglos XVIII, XIX y XX. Barcelona: Ediciones del Serbal, 1998.

GAUVARD, C. "Justiça e paz". In: LE GOFF, J. \& SCHMITT, J.-C. Dicionário temático do ocidente medieval. São Paulo: EDUSC, 2006 (dois volumes).

HABERMAS, J. Teoría de la acción comunicativa. Madrid: Taurus, 1988 (dois volumes).

. Escritos sobre moralidad y eticidad. Barcelona: Paidos/IEC, 1991.

. La inclusión del otro. Estudios de teoría política. Barcelona; Buenos Aires;

México: Paidós, 1999.

Israel o Atenas. Ensayos sobre religión, teología y racionalidad. Madrid:

Trotta, 2001.

. Entre naturalismo y religión. Barcelona; Buenos Aires; México: Paidós, 2006.

HARLEY, D. Condição pós-moderna. São Paulo: Loyola, 1994.

HÖFFE, O. Justicia política. Barcelona; Buenos Aires; México: Paidós, 2003.

JONAS, H. Técnica, medicina y ética. Barcelona; Buenos Aires; México: Paidós, 1997. Memorias. Madrid: Losada, 2005. 
O princípio responsabilidade. Ensaio de uma ética para a civilização tecnológica. Rio de Janeiro: Contraponto, 2006.

LAKATOS, I. In: http://www.philosophy.ru/edu/ref/sci/lakatos.html, acessado em 02 de agosto de 2010.

LOSOVIZ, A. I.; VIDAL, D. A.; BONILLA, A. Bioética e Salud Mental. Intersecciones e dilemas. Buenos Aires: Akadia, 2006, p. 77-88.

KANT, I. Teoria e prática. $3^{\mathrm{a}}$ ed. Madrid: Tecnos, 2000.

MENDIETA, E. "La lingüistificación de lo sagrado como catalítico de La modernidad”. In: HABERMAS, J. Israel o Atenas. Ensayos sobre religión, teología y racionalidad. Madrid: Trotta, 2001, p. 11-50.

MACPHERSON, C. B. Ascensão e queda da justiça econômica e outros ensaios. Rio de Janeiro: Paz e Terra, 1991.

MUGUERZA, J. Desde a perplejidad. México: Fondo de Cultura Econômica, 1990.

PIZZI, J. Ética e éticas aplicadas. A reconfiguração do âmbito moral. Porto Alegre: EDIPUCRS, 2006.

PIZZI, J. "O giro filosófico e as éticas aplicadas". In: Revista Prima Facie, Revista de Ética, $\mathrm{n}^{\circ} .5,1^{\circ}$ de setembro de 2010, http://www.eticus.com/ijva/prima.php?doc=18, acessado em 02 de agosto de 2010.

RABUSKE, E. Epistemologia das ciências humanas. Caxias do Sul: EDUCS, 1987.

RICOEUR, P. ou justo ou a essência da justiça. Lisboa: Instituto Piaget, 1997.

RICOEUR, P. A memória, a história, ou esquecimento. Campinas: Editora Unicamp, 2007.

SIMÓN, P. e BARRIO, I. M. ¿Quién decidirá por mí? Madrid: Triacastela, 2004.

VATTIMO, G. "Muerte o transfiguración de la religión”. In: CALO, J. R. (Ed.). Topografias del mundo contemporáneo. Madrid: Ediciones Encuentro, 1998.

E-mail: jovino.piz@gmail.com

Recebido em: Setembro/2010

Aprovado em: Outubro/2010 